\title{
Linear dimensional changes in plaster die models using different elastomeric materials
}

\begin{abstract}
Jefferson Ricardo Pereira(a)
Karina Yumi Murata(b)

Accácio Lins do Valle ${ }^{(c)}$ Janaina Salomon Ghizoni(d) Fábio Kenji Shiratori(e)
\end{abstract}

(a) PhD, Department of Prosthodontics, Dental School, University of Southern Santa Catarina (UNISUL), Tubarão, SC, Brazil.

(b) DDS; (c)PhD; (e) MSc - Department of Prosthodontics, Bauru Dental School, University of São Paulo (USP), Bauru, SP, Brazil.

(d) MSc, Department of Periodontology, Dental School, University of South of Santa Catarina (UNISUL), Tubarão, SC, Brazil.

\section{Corresponding author:}

Jefferson Ricardo Pereira

Rua Pd Bernardo Freuser, 306-D - Sala 202

Tubarão - SC - Brazil

CEP: 88701-140

E-mail: jeffripe@rocketmail.com

Received for publication on Mar 22, 2010 Accepted for publication on Jun 17, 2010

\begin{abstract}
Dental impression is an important step in the preparation of prostheses since it provides the reproduction of anatomic and surface details of teeth and adjacent structures. The objective of this study was to evaluate the linear dimensional alterations in gypsum dies obtained with different elastomeric materials, using a resin coping impression technique with individual shells. A master cast made of stainless steel with fixed prosthesis characteristics with two prepared abutment teeth was used to obtain the impressions. References points (A, B, C, D, E and F) were recorded on the occlusal and buccal surfaces of abutments to register the distances. The impressions were obtained using the following materials: polyether, mercaptan-polysulfide, addition silicone, and condensation silicone. The transfer impressions were made with custom trays and an irreversible hydrocolloid material and were poured with type IV gypsum. The distances between identified points in gypsum dies were measured using an optical microscope and the results were statistically analyzed by ANOVA $(\mathrm{p}<0.05)$ and Tukey's test. The mean of the distances were registered as follows: addition silicone $(\mathrm{AB}=13.6 \mu \mathrm{m}, \mathrm{CD}=15.0 \mu \mathrm{m}$, $\mathrm{EF}=14.6 \mu \mathrm{m}, \mathrm{GH}=15.2 \mu \mathrm{m})$, mercaptan-polysulfide $(\mathrm{AB}=36.0 \mu \mathrm{m}$, $\mathrm{CD}=36.0 \mu \mathrm{m}, \mathrm{EF}=39.6 \mu \mathrm{m}, \mathrm{GH}=40.6 \mu \mathrm{m})$, polyether $(\mathrm{AB}=35.2 \mu \mathrm{m}$, $\mathrm{CD}=35.6 \mu \mathrm{m}, \mathrm{EF}=39.4 \mu \mathrm{m}, \mathrm{GH}=41.4 \mu \mathrm{m})$ and condensation silicone $(\mathrm{AB}=69.2 \mu \mathrm{m}, \mathrm{CD}=71.0 \mu \mathrm{m}, \mathrm{EF}=80.6 \mu \mathrm{m}, \mathrm{GH}=81.2 \mu \mathrm{m})$. All of the measurements found in gypsum dies were compared to those of a master cast. The results demonstrated that the addition silicone provides the best stability of the compounds tested, followed by polyether, polysulfide and condensation silicone. No statistical differences were obtained between polyether and mercaptan-polysulfide materials.
\end{abstract}

Descriptors: Dental impression materials; Dental impression technique; Dental prosthesis.

\section{Introduction}

Successful dental prosthesis is dependent upon the dimensional precision of impression materials and techniques. The cervical limits of abutment teeth, especially when they are located in subgingival regions, can be unsatisfactory because of the challenges involved in obtaining accurate impressions. This is because the impression materials are not able to keep away gingival tissues, thus methods are needed to handle such tissues to better reproduce structural details in these regions..$^{1-3}$ Many me- 
chanical, chemical or chemical-mechanical methods have emerged to facilitate gingival retraction..$^{4-5}$

Today, many clinicians employ the individual shell technique with mechanical gingival retraction that was initially described by Cannistraci. ${ }^{6}$ Livaditis $^{7}$ favoured the technique of orienting the impression material distribution to mould the gingival sulcus without additional procedures such as retractor wires or chemical substances. However, even with mechanical gingival retraction, the tissue trauma or gingival bleeding is minimal.

Aside from the impression technique, the materials used are also very important in order to obtain gypsum casts. Addition silicones, mercaptanpolysulfides, and polyetheres are the most common additives for this procedure. ${ }^{8-17}$

The thickness of the impression material, in addition to the effects of temperature and the materials used, influences the mould, producing excessive distortion of the impression. ${ }^{9,10}$ The individual shell technique is advantageous because the thickness of the material is less and it thus produces only minor dimensional changes in the impression..$^{9,10}$

In this way, the objective of this study was to analyze the linear dimensional changes of those dental impression materials. The hypothesis was that there was significant difference on the linear dimensional alterations in gypsum dies obtained with different elastomeric materials.

\section{Material and Methods}

One master cast was made with stainless steel, simulating two posterior abutment teeth prepared to receive a fixed prosthesis intercalated between two bridges. The occlusal and vestibular surfaces were marked reference points named A, B, C, D (occlusal), E, F, G, and $\mathrm{H}$ (vestibular). In this way, inter abutment distances $\mathrm{AB}, \mathrm{CD}, \mathrm{EF}$ and $\mathrm{GH}$ can be identified, as shown in Figure 1. The distances between the points $(2,538 \mu \mathrm{m})$ were measured microscopically (Mitutoyo SC-6" - COOE TOO-113, Mitutoyo INC, Kanagawa, Japan). These measurements were compared to those obtained from gypsum casts from a master cast made using the different elastomeric materials.

To ensure the correct positioning of the master cast and the tray, a device aimed at standardizing the position during the impressions was utilized. This device holds the master cast enveloped in a container fabricated with condensation silicone (Elite Double 8, Zhermack, Badia Polesine, RO, Italy) and three resin abutments (Clássico - Artigos Odontológicos, S/A, São Paulo, SP, Brazil) juxtapositioned on a glass plate with dimensions of $12 \times 8 \mathrm{~cm}$.

In the lateral portions of the container were two fixed pivot-abutments to prevent the horizontal displacement of the tray, and in the opposite lateral section, another pivot was fixed to support the cable of the tray while preventing its vertical displacement.

To make the shells, the prosthetic abutments of the master cast were reproduced by alginate (Jeltrate, Dentsply, Petrópolis, RJ, Brazil) and a partial perforated tray, thus producing the preliminary cast (Herodent - Vigodent, Rio de Janeiro, RJ, Brazil). Forty shells made of acrylic resin with the correct cervical adaptation were produced from this preliminary cast.

One individual tray was made to transfer the shells. This tray was composed of a posterior length, and two grooves to allow the tray to keep the same position on the device during the impression, thus preventing all displacement.

The shells were each filled with the four group impression materials to obtain the impressions, five repetitions each, thus resulting in twenty samples. The groupings are as follows; Group MERC: Impres-

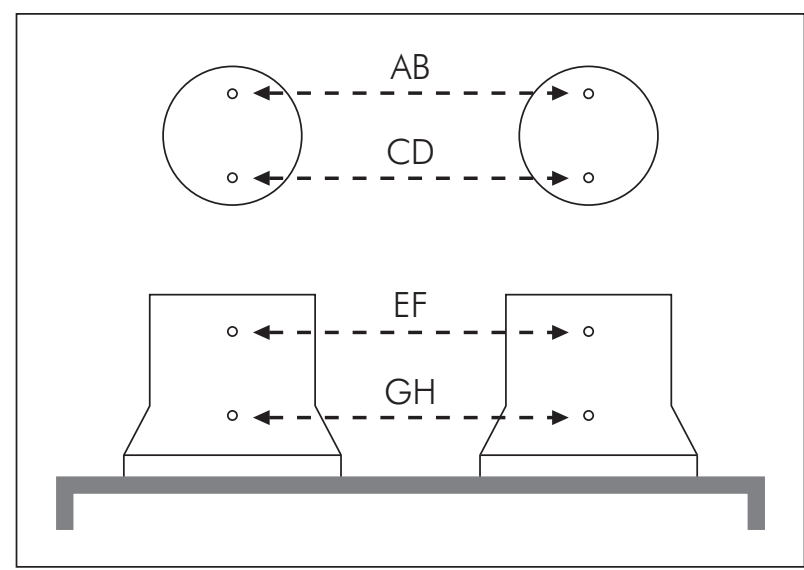

Figure 1 - Schematic drawing representing the master cast and the inter abutment distances (A, B, C and D occlusal) (E, $F, G$ and $H$ vestibular). 
sion with mercaptan-polysulfide (Permlastic Regular - Kerr, Orange, CA, USA); Group CS: Impression with condensation silicone (Optosil/Xantopren - Heraeus-Kulzer, Wasserburg, Germany); Group AS: Impression with addition silicone (Aquasil Soft Putty/Aquasil LV - Dentsply do Brasil, Petrópolis, RJ, Brasil); Group POLY: Impression with polyether (Impregum F - Espe, St. Paul, Minnesota, USA).

A thin layer of adhesive was applied to the shells, as recommended by the manufacturer. After the drying of the adhesive, the impression material was put on the shells, and the shells were slowly positioned on the abutments in the master cast. A static load of $400 \mathrm{~g}$ was applied to the shells during the polymerization of each material. All steps were done by one operator.

In order to the remove the shells, the individual trays were filled with alginate (Jeltrate- Dentsply, Petrópolis, RJ, Brazil) and positioned on the master cast, maintaining the shells in the position favored by the device for the placement of the master cast and tray.

After evaluation, the impressions were poured with special gypsum (Velmix - Kerr, Orange, CA, USA) followed by spatulation in a vacuum for 5 minutes. To further diminish the formation of the bubbles, a vibrator (DCL, Campinas, SP, Brazil) was used to pour the impression, and 45 minutes were allowed to elapse in order to harden the gypsum. The cast gypsum was then removed.

After the casts were evaluated via microscopy with a magnification of 30 times and precision of 5 micrometers (MITUTOYO SC-6" - COOE-113, MITUTOYO INC, Kanagawa, Japan), they were measured using the reference points described above, thus allowing us to obtain the dimension of the inter abutment distances.

The dimensions of master casts and the gypsum casts were obtained by the same observer who had no previous knowledge regarding which group of impression material was used in the casts. The measures of each point were made three times and the final mean was considered to be the distance between the points.

Statistical analysis of the results was performed using analysis of variance (ANOVA) followed by
Tukey test. Values of $\mathrm{p}<0.05$ were considered statistically significant.

\section{Results}

The difference of the distance between the points $(\mathrm{AB}, \mathrm{CD}, \mathrm{EF}$, and $\mathrm{GH})$ from each gypsum cast in relation to the master cast was registered in micrometers. The measures of the distances between the points $(\mathrm{AB}, \mathrm{CD}, \mathrm{EF}$, and $\mathrm{GH})$ were analyzed separately and the mean of the dimensional changes of each of the utilized materials and the standard deviation are reported in Table 1.

Table 2 shows the percentages of alteration related to the master cast.

\section{Discussion}

This study accepted the hypothesis that there was significant difference on the linear dimensional alterations in gypsum dies obtained with different elastomeric materials.

In the clinic, the dental surgeon faces the possibility of destroyed dental elements. According to the level of the destruction of such teeth, professionals have the option to recommend direct or indirect restorations.

One of the most important steps in the indirect metallic or non-metallic restoration is obtaining an accurate impression of the tooth to be restored and its adjacent tissues in attempt to reproduce the correct relationship among all of the structures in the buccal cavity.

In line with this, researchers have established the use of a shell similar to an individual dental tray for a prepared tooth, like an abutment tooth, thus allowing more control of the minimal thickness of the material and generating a smaller disturbance compared to an individual dental tray., ${ }^{2,7}$

With regard to gingival retraction, Dimashkieh and Morgano $^{2}$ reported that the use of the retractor wire was the most popular treatment in comparison to a shell. However, this method takes more time and requires the use of chemical agents that could damage local tissues, cause undesirable systemic effects, and alter the polymerization of the rubber material. In this work, gypsum die abutments from impressions with addition silicone presented lower 


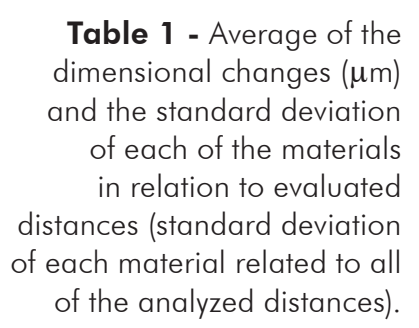

\begin{tabular}{c|c|c|c|c|c|c|c|c}
\hline \multirow{2}{*}{ Material } & \multicolumn{2}{|c}{$A B$} & \multicolumn{2}{c|}{ CD } & \multicolumn{2}{c|}{ EF } & \multicolumn{2}{c}{ GH } \\
\cline { 2 - 9 } & $\bar{X}$ & $d p$ & $\bar{X}$ & $d p$ & $\bar{X}$ & $d p$ & $\bar{X}$ & $d p$ \\
\hline Merc & $36.0^{a}$ & 1.41 & $36.0^{a}$ & 1.00 & $39.6^{a}$ & 1.14 & $40.6^{a}$ & 1.51 \\
\hline Poly & $35.2^{a}$ & 1.48 & $35.6^{a}$ & 0.54 & $39.4^{a}$ & 0.89 & $41.4^{a}$ & 0.89 \\
\hline CS & $69.2^{\mathrm{b}}$ & 1.48 & $71.0^{\mathrm{b}}$ & 1.22 & $80.6^{\mathrm{b}}$ & 1.67 & $81.2^{\mathrm{b}}$ & 0.83 \\
\hline AS & $13.6^{\mathrm{c}}$ & 0.89 & $15.0^{\mathrm{c}}$ & 1.22 & $14.6^{\mathrm{c}}$ & 0.54 & $15.2^{\mathrm{c}}$ & 0.83 \\
\hline
\end{tabular}

Groups with the same letter, in columns, are not statistically different $(P<0.05)$. Merc: mercaptan-polysulfide. Poly: polyether. CS: condensation silicone. AS: addition silicone.

distortion. (Table 1) This was most likely due to the insignificant contraction of the material. In the dental office, this situation enables an accurate adaptation of the metallic structure. The results of the present study confirm the excellent dimensional stability and the reproduction of details achieved when using this material, as described previously. ${ }^{11-13}$

The condensation silicone shows low resistance to rip and higher deformation than other elastomeric materials, and increased distortion when it is stored prior to pouring. The dimensional instability may be due to ethylic alcohol, which could be produced as a by-product of the chemical reaction of this silicone. This was confirmed by comparison of the addition and condensation silicone, indicating the first is a choice material. ${ }^{12}$

The data from the present study confirmed the dimensional instability of the condensation silicone, since the casts from the impressions made with this material presented a higher dimensional linear alteration of the inter abutment teeth $(\mathrm{AB}=69.2 \mu \mathrm{m}$, $\mathrm{CD}=71.0 \mu \mathrm{m}, \quad \mathrm{EF}=80.6 \mu \mathrm{m}, \quad \mathrm{GH}=81.2 \mu \mathrm{m})$. Therefore, we do not recommend the use of condensation silicone in this technique.

To further elucidate the characteristics of polyether, the authors evaluated this common dental clinic material. High elasticity of the polyether was observed. There was difficulty in the removal of the shell and transfer of the impression. However, the shells were removed and carefully repositioned on an alginate mold. The dimensional stability of this material was noted; the abutment dies were a little larger than the master cast (Table 1), but this difference was not clinically significant.

The polyether has a higher modulus of elasticity than mercaptan-polysulfide and the silicones,
Table 2 - Percentages of alteration related to the master cast.

\begin{tabular}{c|c}
\hline Material & $\%$ \\
\hline Merc & 1.50 \\
\hline Poly & 1.49 \\
\hline CS & 2.97 \\
\hline AS & 0.57 \\
\hline
\end{tabular}

Merc: mercaptan-polysulfide. Poly: polyether. CS: condensation silicone. AS: addition silicone.

and it frequently does need a substantial force for its removal from the buccal cavity. ${ }^{11}$ The rigidity and inferior resistance to ripping of the polyether prevented its indication for use in interproximal and subgingival prepared tooth areas. Thus, the authors recommend applying a large amount of material between the tray and prepared tooth area with this compound. The polyether is stable, has less of a permanent deformation than polysulfide, and good reproduction of structural details. The high degree of dimensional stability is explained by the absence of volatile products during polymerization.

Another studied material was polysulfide. It presented similar results to those of polyether. The dimensional stability of polysulfide is low because of the loss of volatile components causing significant contractions in the impression. ${ }^{14}$ The dimensional change of the mercaptan-polysulfide was also due to handling of the material, time of mixture, time of waiting to pour the impression, amount of material, morphological characteristics of the tray, and accommodation of the adhesive. ${ }^{15}$

However, the mercaptan-polysulfide had the same measures of inter-abutment distances as the polyether and addition or condensation silicones 
when an individual tray was used. ${ }^{16,17}$ The polysulfide presented better results than the addition or condensation silicones in the study of the capacity of copy of elastomeric materials. ${ }^{12}$ Despite the abominable smell, fast time of handling, prolongable time of polymerization, and high sensitivity to temperature and humidity, the mercaptan-polysulfide has an effective union with the tray, proper adhesive, and flexible time for the pouring of impressions, low cost, and higher resistance to ripping.

Although many works have confirmed the dimensional instability of mercaptan-polysulfide, ${ }^{14}$ other researchers agree with its good quality. ${ }^{16-17} \mathrm{Be}-$ sides that, in this work, the minimal thickness of the material obtained in the use of the individual shell allowed the secure impression. Therefore, materials not good for obtaining impressions, when used together with the other techniques (i.e.: individual shell), have their qualities raised.

The American Dental Association (ADA) admits dimensional changes of elastomers less than $0.5 \%$ are clinically acceptable. The addition silicone showed $0.57 \%$ of alteration related to the master cast, followed by $1.49 \%$ of polyether, $1.50 \%$ of the mercaptan-polysulfide and $2.97 \%$ of condensation silicone. The authors observed that the addition silicone was the most stable material, while condensation silicone had the higher mean of distortion.

The dies obtained by impression with polyether and mercaptan-polysulfide showed a similar interabutment distance and casts a little bigger than the master cast. This is clinically important because it

\section{References}

1. Millar B. How to make a good impression (crown and bridge). Br Dent J. 2001 Oct;191(7):402-3, 405.

2. Dimashkieh MR, Morgano SM. A procedure for making fixed prosthodontic impressions with the use of preformed crown shells. J Prosthet Dent. 1995 Jan;73(1):95-6.

3. Johnson GH, Mancl LA, Schwedhelm ER, Verhoef DR, Lepe $\mathrm{X}$. Clinical trial investigating success rates for polyether and vinyl polysiloxane impressions made with full-arch and dualarch plastic trays. J Prosthet Dent. 2010 Jan;103(1):13-22.

4. Donovan TE, Chee WW. Current concepts in gingival displacement. Dent Clin North Am. 2004 Apr;48(2):443-4. provides space for the cement agent. Therefore, the polyether and the mercaptan-polysulfide are materials that could indicate the use of the individual shell technique.

The impression materials are produced as a solution to the limitations of the older materials. Thus, dental professionals should be informed about the advantages and disadvantages of each material to adequately use them in clinical practice. As such, the professional will be able to adjust the more precise reproduction of the prepared tooth, aiming for final satisfaction in the case.

\section{Conclusions}

According to results, it is possible to conclude:

- The addition silicone showed the best stability compared to the three other groups, followed by polyether, mercaptan-polysulfide, and condensation silicone.

- Condensation silicone was significantly different from the three other groups.

- Polyether and the mercaptan-polysulfide did not present a significant difference from each other, but they were worse than addition silicone and better than condensation silicone.

\section{Acknowledgements}

The authors would like to thank FAPESP (São Paulo Research Foundation). The authors want to thank Prof. Dr. José Roberto Pereira Lauris for the statistical analysis.

5. Kumbuloglu O, User A, Toksavul S, Boyacioglu H. Clinical evaluation of different gingival retraction cords. Quintessence Int. 2007 Feb;38(2):e92-8.

6. Cannistraci AJ. A new approach to impression taking for crown and bridge. Dent Clin North Am. 1965 Mar;29:3342.

7. Livaditis GJ. The matrix impression system for fixed prosthodontics. J Prosthet Dent. 1998 Feb;79(2):208-16.

8. Rubel BS. Impression materials: a comparative review of impression materials most commonly used in restorative dentistry. Dent Clin North Am. 2007 Jul;51(3):629-42. 
9. Millstein P, Maya A, Segura C. Determining the accuracy of stock and custom tray impression/casts. J Oral Rehabil. 1998 Aug;25(8):645-8.

10. Donovan TE, Chee WW. A review of contemporary impression materials and techniques. Dent Clin North Am. 2004 Apr;48(2):445-70.

11. Farah JW, Clark AE, Ainpour PR. Elastomeric impression materials. Oper Dent. 1981 Jan;6(1):15-9.

12. Johnson GH, Craig RG. Accuracy of addition silicone as a function of technique. J Prosthet Dent. 1986 Feb;55(2):197203.

13. Faria ACL, Rodrigues RCS, Macedo AP, Mattos MGC, Ribeiro RF. Accuracy of stone casts obtained by different impression materials. Braz Oral Res. 2008 Oct-Dec;22(4):293-8.
14. Phillips RW. Skinner's science of dental materials, $10^{\text {th }}$ ed. Philadelphia: WB Saunders; 1996. 709 p.

15. Walters RA, Spurrier S. An effect of tray design and material retention on the linear dimensional changes in polysulfide impressions. J Prosthet Dent. 1990 Mar;63(3):277-81.

16. Johnson GH, Craig RG. Accuracy of four types of rubber impression materials compared with time of pour and a repeat pour of models. J Prosthet Dent. 1985 Apr;53(4):484-90.

17. Boulton JL, Gage JP, Vincent PF, Basford KE. A laboratory study of dimensional changes for three elastomeric impression materials using custom and stock trays. Aust Dent J. 1996 Dec;41(6):398-404. 